\title{
Case Study: Examining the Differences between Donors and Non-donors to an Intercollegiate Athletics Department
}

\author{
Eddie G Walker II", Mikayla D. Jones \\ Business Department, University of Minnesota Crookston, Crookston, 56716, Minnesota, United States
}

Received July 25, 2021; Revised September 16, 2021; Accepted October 17, 2021

\section{Cite This Paper in the following Citation Styles}

(a): [1] Eddie G Walker II, Mikayla D. Jones, "Case Study: Examining the Differences between Donors and Non-donors to an Intercollegiate Athletics Department," Advances in Economics and Business, Vol. 9, No. 3, pp. 55 - 64, 2021. DOI: 10.13189/aeb.2021.090301.

(b): Eddie G Walker II, Mikayla D. Jones (2021). Case Study: Examining the Differences between Donors and Non-donors to an Intercollegiate Athletics Department. Advances in Economics and Business, 9(3), 55 - 64. DOI: 10.13189/aeb.2021.090301.

Copyright $\odot 2021$ by authors, all rights reserved. Authors agree that this article remains permanently open access under the terms of the Creative Commons Attribution License 4.0 International License

\begin{abstract}
Research has provided evidence for a relationship among donor perceptions of social responsibility, trust, commitment, and intentions to donate. One research area lacking is how donors and non-donors to an institution differ in those factors. Communication between an institution and stakeholders helps build understanding and support. One approach to communication strategies includes the varying involvement of the stakeholders. This study endeavors to accomplish two goals: 1) to fit the data from a purposive sample to a validated model; and 2) to examine differences between donors and non-donors on the factors within that model. Results indicated that the data from this case study fit the theoretical model. Also, while donors and non-donors defined the factors in the model in similar ways, there were differences between donors and non-donors related to the intensity of the relationships between factors. Donors demonstrated a stronger relationship between trust/commitment and commitment/intent than non-donors did. Non-donors demonstrated a stronger relationship between trust/intent than donors did. One implication of this study is that universities and athletic departments can use information from the results to aid them in communicating with donors and alumni during fundraising campaigns. Specifically, if you can communicate with stakeholders in a way that increases trust and commitment to the institution then they would likely strengthen the donation intentions of current donors and encourage
\end{abstract}

non-donors to donate in the future. Future research can build upon this study by determining the effects that a stakeholder involvement communication strategy would have on non-donor donation intentions.

Keywords Communication, Corporate Social Responsibility, Donation Intentions, Consumer Behavior

\section{Introduction}

Many intercollegiate athletic departments struggle to finance their growing athletic demands with irregular funding from donors [1,2]. When examining the profitability of intercollegiate athletic departments, a recent National Collegiate Athletic Association (NCAA) Revenues and Expenses report that only 25 of 351 Division I athletics programs reported profits for the 2019 fiscal year [3]. Factor in the decreasing state appropriations to higher education, and it is no surprise that universities rely on fundraising to fill the gap. In order to successfully attract donors, universities must demonstrate that they are providing some return on investment to meet the expectations of philanthropic donors [4]. This can be done in a variety of ways, with one method being undertaking philanthropic initiatives that enhance the image of the university as well as giving 
back to the community.

According to Koo and Dittmore [5], "the success of intercollegiate athletics has been used as a powerful communication tool that increases good publicity and enhances the university profile, which could, in turn, result in favorable private giving" (p. 2). While athletic success is one avenue of demonstrating value to donors, athletic success is not something in a development office's control. This raises a question about whether there are other avenues exist to demonstrate value to donors. Past models have used initiatives like corporate social responsibility (CSR)/philanthropy to demonstrate value.

With decreasing government funds, universities are using marketing and branding to increase revenues, such as donations [6]. Stephenson and Bell [6] found that the top three reasons for donating to the university were related to social identity (e.g., I donate because I am an alumna/us). In this same study, the reasons that non-donors gave for not donating were more varied, but also seemed related to social identity. For example, some alumni responded that they either stopped donating or do not donate because their school changed the mascot/logo (e.g., ...the school changed to a place I no longer recognize). While some reasons for not donating cannot be helped (i.e., the alumna/us cannot afford to donate), there are ways to increase the level of social identity with a university in a positive manner. While this study provides specific reasons for donating (or not), theoretical models describing donor behavior have focused entirely on donors. The primary purpose of this case study is to take one of these models and compare how it fits the data collected from a purposeful sample of donors and non-donors at a Midwestern United States university.

\subsection{Corporate Social Responsibility}

Corporate social responsibility (CSR) has been part of the strategic mission of organizations worldwide as a means of giving back to their respective societies. Researchers have demonstrated that CSR initiatives can positively affect profits, growth, and consumer attitudes; and organizations are clamoring to seize those opportunities. [7]. CSR is relevant to organizations of all types and sizes, including unique organizations like charity or sport. According to Smith and Westerbeek [8], sport is an ideal vehicle for implementing CSR because "sport possesses the power to captivate and unite individuals within communities and create environments for contributing to social capital" (p. 52).

Because of the growing popularity of CSR within sport, there has been an extensive amount of research conducted related to CSR. Research on motives and benefits from participating in CSR $[9,10]$, measuring the effectiveness of implemented initiatives [11,12], and consumer reactions to and perceptions of CSR [13,14]. This provides evidence that CSR can have a positive impact on consumer's perceptions about an organization. These positive perceptions can lead to increased trust and identity salience from consumers [15]. Higher levels of identity salience can also strengthen stakeholder monetary support and loyalty for an organization associated with specific CSR initiatives. However, Marin, Ruiz, and Rubio [16] state that connecting a product or brand to a social identity must consider the extent to which that social identity holds value for the consumers. This determines the perceptions that the consumer may have of any CSR initiatives undertaken by the organization. One example where perceptions of CSR initiatives may be negative occurs in a phenomenon known as greenwashing [17]. Greenwashing occurs when organizations use CSR to distract stakeholders from their irresponsible actions and decisions, creating negative perceptions of their CSR.

As within business, CSR initiatives vary greatly in their focus and intentions within sport [Babiak-Routledge]. Babiak and Wolfe [18] identified six pillars of CSR related to the sport industry. Organizations can use these pillars to determine how and to what extent they wish to incorporate CSR into their strategic plans. The six pillars are: labor relations, environmental management/sustainability, community relations, philanthropy, diversity/equity, and corporate governance.

\subsubsection{Labor Relations}

The first pillar relates to labor relations. Organizational leaders who choose this focus would ask in what ways we can better treat our employees. Babiak and Wolf [18] argued that organizations have a moral obligation to make decisions that focus on the well-being of their employees (to include CSR initiatives conducted). A current instance where sport organizations have implemented a CSR initiative focused on the well-being of their employees was the National Football League (NFL) promoting and pledging \$250 million and counting for social justice initiatives that were important to their players [19].

\subsubsection{Environmental Management/Sustainability}

The second pillar relates to environmental management and sustainability. In general, many organizations include environmental sustainability initiatives within their strategic plan [18]. As it relates to sport, organizations are taking the same approach. In some instances, sport organizations have instituted environmental-related CSR initiatives to address potential negative impacts sport can have on the environment. Also, these initiatives can be demonstrated to stakeholders the organizational commitment to the environment and the community. Specifically, media scrutiny related to the environmental impact of the organization (e.g., facility "green" designs) can be utilized to communicate the CSR initiatives conducted by the organizations [20].

\subsubsection{Community Relations}

Organizations may focus on CSR initiatives as a vehicle for improving community relationships and the 
environment in which they operate. Professional sport leagues such as the National Basketball League (NBA) and the NFL use community relations CSR initiatives to demonstrate their commitment to their respective communities. Initiatives such as NBA Cares and NFL Play 60 are their important social initiatives. These initiatives are community-based initiatives that encourage youth to excel academically (NBA Cares) and be physically fit by being active at least 60 minutes per day (NFL Play 60) [18].

\subsubsection{Philanthropy}

Organizations will use philanthropic giving as another means of giving back to the community, usually through a foundation [18]. With state and federal governments spending less money on higher education, colleges and universities are relying more on other sources of revenue, specifically donations [6]. One study that is particularly relevant to this study demonstrated that vicarious achievement, philanthropy, commitment, and power were four motivational factors in donors' giving to a NCAA Division II university [21].

\subsubsection{Diversity/Equity}

Organizations may use CSR as a means of promoting an inclusive work environment as well as ensuring the work place is reflective of society [18]. The NFL has done this by implementing the "Rooney Rule", which ensures access to minority candidates to head coaching and front office jobs by requiring teams to interview at least one minority candidate for any high-level job opening. In addition, the NFL has demonstrated their commitment to diversity and equity by their continued funding of social justice initiatives mentioned earlier.

\subsubsection{Corporate Governance}

The final pillar relates to corporate governance. This is a broad pillar with the goal of making sure all levels of the organization are working together to give the organization a sense of direction as well as developing policy [18]. In the past, it has been important for professional leagues to mitigate the impact of scandals within their respective sports. The NFL instituted stronger concussion protocols, setting aside $\$ 765$ million for retired players after a rash of lawsuits related to the development of chronic traumatic encephalopathy (CTE) resulting from repeated concussions, and funding research grants to study the effects of head injuries [22].

\subsection{Influencing Donation Intentions}

As mentioned in the previous section, there are benefits from CSR initiatives no matter what the organizational focus is. As a result, researchers are interested in if said initiatives can influence donation intentions, specifically within nonprofit organizations like intercollegiate athletic departments or youth sport teams. This question relates to the fourth CSR pillar mentioned previously: philanthropy. Ko et al. [15] specifically created a theoretical model that tested the relationship among trust, perceptions of organizational CSR, donor commitment, and intention to donate. (Figure 1). Their model provides evidence that trust and commitment are mediating factors of the effects of perceptions of CSR on donation intentions. This model demonstrated that there is an indirect effect of CSR perceptions on trust and commitment. The model also outlined a direct effect of trust on commitment and donation intentions as well as a direct effect of CSR perceptions and commitment on donation intentions. Since they used a sample of donors to a university, this model has proven beneficial in explaining donors' donation behaviors. However, it is not clear if non-donors differ from donors in these specific factors within the model. While there are other factors that influence donations (like athletic success), this model was selected as a means to examine the differences between donors and non-donors specifically because communication efforts of alumni relations can speak to initiatives and experiences that could enhance stakeholder perceptions of the university's social responsibility, trust, and commitment. Enhancing these factors can then lead to increased intentions to donate.

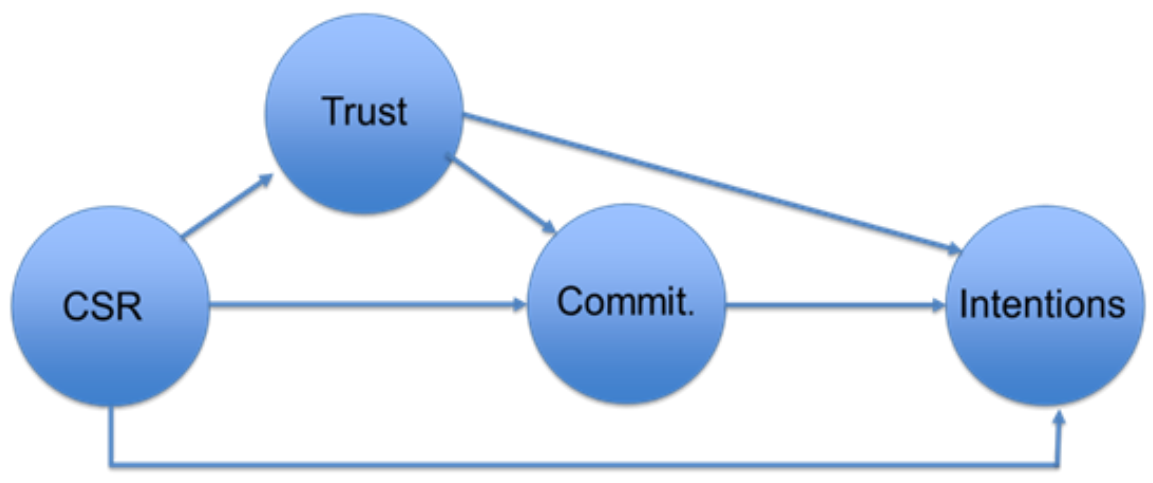

Figure 1. Ko et. al's Model Including Trust as a Mediating Factor in the Relationship Among Perceptions of CSR (CSR), Commitment, and Donation Intentions 
According to Wastyn [23], "only when we understand the decision-making process of non-donors can we begin to find more effective ways to encourage giving" (pg. 99). Since intercollegiate athletic departments are becoming more reliant on donations, if administrators have insight into how non-donors can be encouraged to become donors, they could develop new strategic initiatives. These initiatives can not only reinforce the relationship developed with current donors but also develop new relationships with non-donors that would lead them to become donors. Ko et al.'s model was developed by examining the mediating effect of trust and commitment on the relationship between perceptions of corporate social responsibility and donation intentions on a group of donors. This model does not determine if this relationship exists for non-donors. With that, this study builds upon previous research by determining if the relationships between the constructs within this model are the same for donors and non-donors within a case study at a NCAA Division II university in the United States. Also, this study builds upon previous research by determining if the relationships between the constructs of this model demonstrate the same intensity for donors and non-donors.

\section{Hypotheses}

As mentioned before, Ko et al.'s initial model indicated a mediating effect of trust and commitment on donor's intentions to continue donating to a university's athletic department. Before group differences can be assessed, it will be important to determine if the data from this case study fits their model. The expectation is that the overall data will fit the model. In order to test if Ko et al.'s model applies equally to both donors and non-donors, the first step is to assess configural invariance. If configural invariance is achieved, both donors and non-donors associate the same items from the survey with the same construct. Therefore, the first hypothesis $\left(\mathrm{H}_{\text {form }}\right)$ below assumes configural invariance.

$$
\mathrm{H}_{\text {form }}: \Lambda_{\text {form }}^{(\text {Donors })} \therefore \Lambda_{\text {form }}^{(\text {Non-donors })}
$$

The second step within the comparison of donors and non-donors is to assess construct-level metric invariance. If this form of metric variance is achieved, then the strength of the relationship between the group of items and their associated construct is the same for both donors and non-donors. The second hypothesis $\left(\mathrm{H}_{\Lambda}\right)$ below assumes metric invariance.

$$
\mathrm{H}_{\Lambda}: \Lambda^{\text {(Donors) }} \therefore \Lambda^{\text {(Non-donors) }}
$$

\section{Materials and Methods}

Ko, et al.'s [15] survey was utilized to examine the relationship among perceptions of CSR, trust, commitment, and donation intentions to determine if there were differences between donors and non-donors at an NCAA Division II university in the United States. Prior to data collection, Institutional Review Board (IRB) approval was obtained and recruitment of respondents began with the help of the alumni relations office. Respondents reviewed and provided informed consent prior to completing the questionnaire using Qualtrics. Path analyses were conducted to determine if the overall data fit the model and if there were differences between donors and non-donors. A critical value of $\mathrm{p}<.05$ was established to determine the significance of each path within the model. Version 27 of SPSS was used to calculate descriptive statistics, correlations, and assess for multicollinearity. Amos Version 27 was used for all path analyses.

\subsection{Target Population and Respondents}

The university's Office of Development and Alumni Relations assisted with the logistics of surveying donors and alumni (who also could be donors or potential donors) by providing available contact information for an initial recruitment effort via an introductory postcard with a link to the Qualtrics survey. This resulted in a target population of 1,929 current donors and alumni. There were 175 people who responded to the survey for a 9 percent response rate. Respondents ranged from 22 to 82 years old $(M=45.5, S D=15.5)$. Table 1 displays the demographic characteristics of the respondents.

Table 1. Demographic Information for all Respondents (Gender, Past Student-Athlete Status, and Donor Status)

\begin{tabular}{ccc}
\hline Demographic Category & Sample Count $(\boldsymbol{n}=)$ & $\%$ \\
\hline Gender & 102 & $58.3 \%$ \\
Male & 51 & $29.1 \%$ \\
Female & & \\
Former Student-Athlete & 89 & $50.9 \%$ \\
Yes & 63 & $36.0 \%$ \\
No & 74 & $42.3 \%$ \\
Donor & 25 & $14.3 \%$ \\
One-Time & 62 & $35.4 \%$ \\
Annual & 78 & $44.6 \%$ \\
Non-donor & &
\end{tabular}

\subsection{Survey}

Past research has demonstrated a relationship among donors' perceptions of an organization's corporate social responsibility (perceived corporate social responsibility), trust of an organization (trust), commitment to the organization (commitment), and intentions to donate to an organization (intentions). Ko and colleagues

[15] 
developed a reliable 12-item survey assessing the aforementioned four components within donors of an organization. This survey was utilized in this study to assess the differences between donors and non-donors of the university within this case study.

\subsubsection{Perceived Corporate Social Responsibility}

There were three items utilized to assess perceptions of the institution's corporate social responsibility. Specifically, these questions assess the extent to which donors and potential donors believe the institution is a socially responsible member of the community. Respondents indicated their level of agreement to individual questions on a seven-point Likert scale ranging from strongly disagree (1) to strongly agree (7). The reliability of this scale was acceptable with Cronbach's $a$ $=.911$. Table 2 displays the mean responses for all who responded to this set of questions.

Table 2. Mean Responses for all Respondents on Social Responsibility Perception Questions

\begin{tabular}{lllll}
\hline & $\boldsymbol{N}$ & $\boldsymbol{M}$ & $\boldsymbol{S D}$ \\
\hline $\begin{array}{l}\text { The athletics department is concerned with } \\
\text { social responsibility }\end{array}$ & 140 & 5.33 & 1.28 \\
$\begin{array}{l}\text { The athletics department is socially } \\
\text { responsible }\end{array}$ & 139 & 5.24 & 1.35 \\
$\begin{array}{l}\text { The athletics department is a responsible } \\
\text { member of our community }\end{array}$ & 139 & 5.68 & 1.27 \\
\hline
\end{tabular}

Note. $M=$ mean response. $S D=$ standard deviation. Higher means indicate a stronger level of agreement. Values of 4 indicate a neutral response.

\subsubsection{Trust}

There were three items utilized to assess trust. Respondents indicated their level of agreement to the trust questions on a seven-point Likert scale ranging from strongly disagree (1) to strongly agree (7). The reliability of this scale was acceptable with Cronbach's $a=.942$. Table 3 displays the mean responses for all who responded to this set of questions.

Table 3. Mean Responses for all Respondents on Trust Questions

\begin{tabular}{cccc}
\hline & $N$ & $M$ & $S D$ \\
\hline The athletics department is trustworthy & 140 & 5.44 & 1.52 \\
I trust the athletics department & 139 & 5.42 & 1.57 \\
I have trusted the athletics department & 139 & 5.59 & 1.44 \\
\hline
\end{tabular}

Notes. $M=$ mean response. $S D=$ standard deviation. Higher means indicate a stronger level of agreement. Values of 4 indicate a neutral response.

\subsubsection{Commitment}

There were three items utilized to assess commitment to the institution. Respondents indicated their level of agreement to individual questions on a seven-point Likert scale ranging from strongly disagree (1) to strongly agree (7). The reliability of this scale was acceptable with Cronbach's $a=.803$, although not as high as the other scales from Ko et al.'s (2014) survey. Table 4 displays the mean responses for all who responded to this set of questions.

Table 4. Mean Responses for all Respondents on Commitment Questions

\begin{tabular}{llll}
\hline & $N$ & $M$ & $S D$ \\
\hline $\begin{array}{l}\text { Being a donor of the athletics department is } \\
\text { important to me }\end{array}$ & 138 & 4.77 & 1.74 \\
$\begin{array}{l}\text { I am a committed donor to the athletics } \\
\text { department }\end{array}$ & 134 & 4.13 & 1.93 \\
$\begin{array}{l}\text { It would be unlikely for me to change my } \\
\text { allegiance from the athletics department }\end{array}$ & 136 & 4.71 & 1.71 \\
\hline
\end{tabular}

Notes. $M=$ mean response. $S D=$ standard deviation. Higher means indicate a stronger level of agreement. Values of 4 indicate a neutral response.

\subsubsection{Donation Intentions}

There were three items used to assess general intentions to continue donating (or to begin donating) to the university. Respondents indicated their level of agreement to individual questions on a seven-point semantic differential scale used by Ko et al. [15]. The reliability of this scale was acceptable with Cronbach's $a=.804$. Table 5 displays the mean responses of all who responded to this set of questions.

Table 5. Mean Responses for all Respondents on Intentions Questions

\begin{tabular}{cccc}
\hline $\begin{array}{c}\text { My future donation to the athletics } \\
\text { department is - }\end{array}$ & $\boldsymbol{N}$ & $\boldsymbol{M}$ & $\boldsymbol{S D}$ \\
\hline Impossible: Possible & 107 & 5.33 & 1.76 \\
& 115 & 3.46 & 1.90 \\
Very Likely: Very Unlikely & 107 & 5.01 & 1.70 \\
Improbable: Probable & & & \\
\hline
\end{tabular}

Notes. $M=$ mean response. $S D=$ standard deviation. Values of 4 indicate a neutral response. Means lower than 4 associated with the left word in the pair; means higher than 4 associated with the right word in the pair. 


\section{Results}

Table 6. Means $(M)$, Standard Deviations $(S D)$, and Correlations for all Variables $(N=123)$

\begin{tabular}{|c|c|c|c|c|c|c|c|}
\hline & Variable & 1 & 2 & 3 & 4 & $M$ & $S D$ \\
\hline 1. & SRAvg & & $\begin{array}{c}.726 \\
*\end{array}$ & $\begin{array}{c}.514 \\
*\end{array}$ & $\begin{array}{c}.478 \\
*\end{array}$ & 5.43 & 1.17 \\
\hline 2. & TrustAvg & & & $\begin{array}{c}.563 \\
*\end{array}$ & $\begin{array}{c}.613 \\
*\end{array}$ & 5.48 & 1.43 \\
\hline 3. & $\begin{array}{l}\text { CommitAv } \\
\mathrm{g}\end{array}$ & & & & $\begin{array}{c}.622 \\
*\end{array}$ & 4.52 & 1.53 \\
\hline 4. & IntentAvg & & & & & 4.94 & 1.50 \\
\hline
\end{tabular}

In order to test that the data fit Ko et al.'s model, any respondents who did not respond to all questions were deleted. The rest 99 respondents are used in the analysis. Due to the sample size, a path analysis was utilized instead of a structural equation model using Stage et al.'s 20 participants per parameter or variable measures. A structural equation model would determine model fit using the individual questions from the survey as a representation of the latent factors within the model due to the complexity associated with those latent factors. In this instance, a path analysis is an appropriate way to analyze the model because the measures used to identify each of the four factors in the model are observable when compared to other complex constructs [24]. An initial path analysis was conducted to determine the fit of the data to the previously mentioned model (Figure 1). For the path analysis, the three questions assessing each factor were averaged together to come up with each endogenous variable used within the model. The hypothesized model included four factors: respondent's perceptions of social responsibility (SRAvg), trust (TrustAvg), commitment (CommitAvg), and intentions to donate (IntentAvg). With multiple variables within the model, one concern is multicollinearity. Correlations for all variables in the path analysis are displayed in Table 6 .

To further assess multicollinearity, perceptions of corporate social responsibility, trust, and commitment were utilized in a linear regression to predict donation intentions for each group (donors and non-donors) to calculate the percent of the variance in donation intentions explained by the predictors and the variance inflation factors (VIF) for said predictors. Among donors, the predictors accounted for $43.6 \%$ of the variance and all VIF values were $<2.67$. Among non-donors, the predictors accounted for $32 \%$ of the variance and all VIF values were $<2.06$. Since all VIF values were below five, multicollinearity was not a concern [25].

The goodness of fit was assessed using three different fit indexes: model chi-square, standardized root mean squared residual (SRMR), and comparative fit index (CFI). Before group differences were assessed, the overall fit to Ko et al.'s model was calculated. The fit indices for this data were: $\chi 2(1)=1.84, p=.175$, SRMR $=.0237$, and CFI $=.995$, indicating the current data demonstrate an acceptable fit. The ideal value for SRMR is less than .08, and CFI greater than 95 [20]. Table 7 displays the unstandardized path estimates for the model with significant paths identified. In the overall model, all paths are significant with the exception of the indirect effect of perceptions of CSR on commitment and the direct effect of perceptions of CSR on donation intentions.

Table 7. Unstandardized Estimates for all Paths in the Model

\begin{tabular}{|c|c|c|c|c|c|c|}
\hline & & & Estimate & S.E. & $\mathbf{C R}$ & $p$ \\
\hline \multicolumn{7}{|c|}{ Indirect Effect } \\
\hline TrustAvg & $<--$ & SRAvg & .884 & .085 & 10.42 & $* *$ \\
\hline CommitAvg & $<---$ & SRAvg & .256 & .155 & 1.65 & .099 \\
\hline \multicolumn{7}{|c|}{ Direct Effect } \\
\hline CommitAvg & $<---$ & TrustAvg & .500 & .127 & 3.93 & $* *$ \\
\hline IntentAvg & $<--$ & TrustAvg & .395 & .118 & 3.35 & $* *$ \\
\hline IntentAvg & $<--$ & CommitAvg & .374 & .087 & 4.30 & $* *$ \\
\hline IntentAvg & $<--$ & SRAvg & -.010 & .135 & -0.07 & .943 \\
\hline
\end{tabular}

Notes. Critical Ratio (CR) values refer to number of standard errors above zero of the calculated estimate. $*=p<.05 . * *=p<.001$ 


\subsection{Donor and Non-Donor Comparison}

The second path analysis was conducted to test the hypotheses related to the differences between donors and non-donors using the same model. The fit indices for the multi-group configural model were: $\chi 2(2)=10.42, p$ $=.005$, SRMR $=.0799$, and CFI $=.940$, indicating the current data demonstrate configural invariance across both donors and non-donors. Ideal value for SRMR is less than .08. For CFI, a value greater than .95 is preferred, but greater than .90 is acceptable [26]. Therefore, the first hypothesis of configural invariance is supported. Table 8 displays the unstandardized path estimates for the model with significant paths identified. The significant paths for donors included the indirect effect of perceptions of CSR initiatives on trust, the direct effect of trust on commitment, and the direct effect of commitment on donation intentions. For non-donors, the significant paths included the indirect effect of perceptions of CSR initiatives on trust, the direct effect of trust on commitment, and the direct effect of trust on donation intentions. Further analysis was conducted to determine metric variance and determine the sources of said variance. Within a structural equation model, this is a three-step process [27]. First, all groups would be analyzed using the same structural model (configural model). Second, all factors in the model would be constrained and then compared to the configural model using the CFI difference test. If metric invariance is detected, the final step would be to determine if any item from the survey could be the source of the invariance. Since the survey was averaged to come up with the observed factors, once invariance is detected for one or more of the factors, the final source of the variance has been detected.

\subsubsection{Construct-Level Metric Invariance}

To determine if the factors were similarly measured across donor status (and there are real differences among donors and non-donors on these factors) all factor loadings were constrained for a comparison model. By utilizing the CFI difference test $(\Delta \mathrm{CFI})$, the difference between the configural model and a model where all paths were constrained was calculated. For the configural model, $\mathrm{CFI}=.940$. When all paths were constrained, $\mathrm{CFI}=.927$, which resulted in $\triangle \mathrm{CFI}=.013$. The threshold for $\triangle \mathrm{CFI}$ $=.01$, which indicated construct-level metric variance between donors and non-donors [28].

\subsubsection{Source of Construct-level Metric Invariance}

To determine how donors and non-donors differed among the different factors, $\triangle \mathrm{CFI}$ for each path was calculated by constraining each path one at a time. Any path with a $\Delta$ CFI $>.01$ indicated a significant difference between donors and non-donors. Table 9 displays the paths where donors and non-donors differ significantly. While donors and non-donors did not differ in the intensity of the indirect effects, they did differ in intensity for three of the four direct effects in the model.

Table 8. Group Comparisons (Donors and Non-Donors) of Unstandardized Estimates for all Paths in the Model

\begin{tabular}{|c|c|c|c|c|c|c|c|c|c|c|}
\hline & & & \multicolumn{4}{|c|}{ Donors } & \multicolumn{4}{|c|}{ Non-Donors } \\
\hline & & & Estimate & S.E. & CR & $p$ & Estimate & S.E. & CR & $p$ \\
\hline \multicolumn{11}{|c|}{ Indirect Effect } \\
\hline TrustAvg & $<---$ & SRAvg & .685 & .095 & 7.17 & $* *$ & .894 & .130 & 6.86 & $* *$ \\
\hline CommitAvg & $<--$ & SRAvg & .113 & .201 & 0.56 & .573 & .191 & .166 & 1.15 & .250 \\
\hline \multicolumn{11}{|c|}{ Direct Effect } \\
\hline CommitAvg & $<---$ & TrustAvg & .711 & .214 & 3.32 & $* *$ & .260 & .128 & 2.04 & $.042 *$ \\
\hline IntentAvg & $<---$ & TrustAvg & .091 & .187 & 0.48 & .628 & .269 & .091 & 2.96 & $.003 *$ \\
\hline IntentAvg & $<---$ & CommitAvg & .258 & .117 & 2.21 & $.027 *$ & .164 & .095 & 1.73 & .084 \\
\hline IntentAvg & $<---$ & SRAvg & -.132 & .158 & -0.84 & .402 & -.050 & .115 & -0.44 & .661 \\
\hline
\end{tabular}

Notes. Critical Ratio (CR) values refer to number of standard errors above zero of the calculated estimate. $*=p<.05 . * *=p<.001$

Table 9. CFI Fit for Multiple Group Analyses of Donation Intentions as Predicted by CSR Perceptions, Trust, and Commitment Across Donor Status

\begin{tabular}{ccccccc}
\hline & & Path Constrained & & CFI & $\Delta$ CFI & Sig. \\
\hline & & Indirect Effect & & & & \\
\hline TrustAvg & $<---$ & & SRAvg & .940 & .000 & NS \\
CommitAvg & $<---$ & & SRAvg & .946 & .006 & NS \\
\hline & & Direct Effect & & & & \\
\hline CommitAvg & --- & & TrustAvg & .918 & .022 & $*$ \\
IntentAvg & $<---$ & & TrustAvg & .927 & .013 & $*$ \\
IntentAvg & $<---$ & & CommitAvg & .923 & .017 & $*$ \\
IntentAvg & ---- & & SRAvg & .930 & .010 & NS \\
\hline
\end{tabular}

Notes. $\Delta \mathrm{CFI}=$ Change in CFI compared to configural model. $*=\Delta \mathrm{CFI}$ is greater than .010 threshold 


\section{Discussion}

The initial path analysis that did not take donor status into account demonstrated the data from this case study fit the original model [15]. The results of the multi-group path analysis supported the first hypothesis of configural invariance. Both donors and non-donors associated the items in the survey with the same constructs. This is important because it demonstrates that donors and non-donors interpret the constructs of perceptions of CSR, trust, commitment, and donation intentions. Since the constructs are interpreted the same by donors and non-donors, administrators would not have to communicate differently with donors and non-donors with respect to perceptions of CSR, trust, and commitment as a means of encouraging continued and future donations to an intercollegiate athletics program.

However, the second hypothesis of construct-level metric invariance was not supported. There were differences between donors and non-donors related to the strength of the relationships between the items in the survey and their constructs. Donors demonstrated a stronger relationship between trust and commitment than non-donors. This means that for non-donors to attain the same level of commitment as donors, they would need to have almost three times the amount of trust in the organization than donors. Also, trust had more than twice the effect on donation intentions for non-donors than donors. This was expected as it is likely that donors already have a higher level of trust in the organization due to their donor status. Therefore, if initiatives or communications from an organization can increase the amount of trust non-donors have in an organization, then there is a greater chance that non-donors will become donors in the future. Finally, commitment demonstrated almost twice the effect on the donation intentions of donors than non-donors. Therefore, to increase the donation intentions of non-donors, they would need to almost double their level of commitment to the institution to achieve the same level of donation intentions of donors. To summarize, increasing stakeholders' trust and commitment to an institution could increase donation intentions in all stakeholders (regardless of current donor status). These results could have implications on how fundraisers for intercollegiate athletic departments interact and communicate with all of their stakeholders.

\section{Conclusion}

When reviewing the six sport-related CSR pillars, it is evident that communication is an important factor in the focus organizations will take related to choosing CSR initiatives [18]. Walker, Kent and Vincent [29] also provided evidence that effective communication can positively influence how stakeholders perceive CSR initiatives. In addition, they contend it is critically important that organizations raise awareness of these initiatives due to the time and money invested in conducting CSR initiatives. Organizations may also enhance their image by maintaining an effective and cohesive communication strategy. Improper communication, on the other hand, can lead to the aforementioned phenomenon of greenwashing [17]. If stakeholders perceive that organizations are conducting CSR initiatives for selfish reasons, then they may not trust the organization as much or be as committed to the organization. The results of this study demonstrate how trust and commitment are positively related to donation intentions. This issue makes effective communication strategies a necessity for all organizations, including athletic departments. Specifically, if athletic departments communicate more effectively with non-donors (while still keeping the connection with donors), they may be able to encourage more non-donors to become donors. An example of more effective communication that might entice non-donors to become donors is highlighting different CSR initiatives being conducted by the athletic department and transparency related to the purposes of these initiatives. Using the model supported in this study might lead to increased non-donor trust that would lead to an increase in commitment. This increase in trust and commitment would then lead to an increase in non-donor donation intentions.

With that, it would be incumbent upon sport organizations to develop an effective communication plan, especially those seeking philanthropic giving from stakeholders. Morsing and Schultz [30] outlined three different CSR communication strategies: stakeholder information strategy, stakeholder response strategy, and stakeholder involvement strategy. For each of the three communication strategies, they provided comparisons related to eight characteristics: communication ideal, sensemaking/sensegiving, stakeholders, stakeholder role, identification of CSR focus, strategic communication task, corporate communication department's task, and third-party endorsement of CSR initiatives. Ideally, communication strategies progress from a one-way form of communication to a two-way, symmetric form of communication.

The stakeholder information communication strategy is one that involves informing stakeholders of initiatives taking place or other relevant aspects of the organization. This strategy is a one-way form of communication where the stakeholders have no say in CSR initiatives conducted by the organization but it "gives sense" to stakeholders by providing them with information related to the organization's current state (e.g., what are the organization's current CSR initiatives). Stakeholders can then request more information concerning any CSR initiatives being pursued. The stakeholder response communication strategy is different from the first communication strategy in that stakeholder preferences 
are taken into consideration. This asymmetrical relationship leaves the corporation with more say in the decision-making process but is an important step in the communication process by determining which CSR initiatives are desirable to stakeholders and which ones are not. Organizations endeavor to determine desirable initiatives by conducting market research with external stakeholders. Stakeholder responses can be used to identify future initiatives, which are then shared with stakeholders (similar to the stakeholder information strategy). Finally, the stakeholder involvement communication strategy is a two-way, symmetric strategy that takes the stakeholder response communication strategy to another level by having stakeholders actively involved in initiatives (either in the development of the initiatives or as participants in the implementation of the initiatives). Instead of an organization determining CSR initiatives by interpreting what is desirable to stakeholders, organization leaders have a dialogue with stakeholders. This dialogue can lead to changes in the perceptions stakeholders have of the organization as well as what CSR initiatives are developed by the organization.

\subsection{Future Directions}

One limitation of this study is that the sample of this study comes from the stakeholders of a single institution. While this is a case study, the procedures used here could be used to confirm similar differences between donors and non-donors at other institutions. Also, communication strategies were not taken into account when fitting the data to this particular theoretical framework. Building upon the results of this study, future research can determine the effect of the three different communication strategies on stakeholder's perceptions of CSR, trust, and commitment. Specifically, it would be beneficial to determine if the stakeholder involvement strategy significantly increases positive perceptions of an organization's CSR, trust, and commitment, resulting in an increase in donation behaviors/intentions.

\section{Acknowledgements}

We are very grateful to our university's Office of Development and Alumni Relations for their assistance in sending the survey to stakeholders.

\section{REFERENCES}

[1] J. M. Gladden, D. F. Mahoney, \& A. Apostolopoulou. Toward a better understanding of college athletic donors: What are the primary motives? Sport Marketing Quarterly, Vol.14, 18-30, 2005
[2] Y. J. Ko \& Y. K. Kim. Determinants of consumers' attitudes toward a sports sponsorship: A tale from college athletics. Journal of Nonprofit \& Public Sector Marketing, Vol.26, 185-207, 2014

[3] D. L. Fulks. Revenues \& Expenses, 2004-2019. NCAA Division I Intercollegiate Athletics Programs Report. National Collegiate Athletic Association, 2020.

[4] K. E. W. Farley. Can private donations help public universities build bridges over troubled waters?: Practical lessons for administrators and donors. Public Organization Review, 18(2), 175-190, 2018.

[5] G. Koo \& S. W. Dittmore. Effects of intercollegiate athletics on private giving in higher education. Journal of Issues in Intercollegiate Athletics, 7(1), 1-16, 2014.

[6] A. 1. Stephenson \& N. Bell. Motivation for alumni donations: a social identity perspective on the role of branding in higher education. International Journal of Nonprofit \& Voluntary Sector Marketing, Vol. 19, No. 3, 176-186, 2014.

[7] European Commission. Green paper: Promoting a European framework for corporate social responsibility. Office for Official Publications of the European Communities, 2001.

[8] A. C. T. Smith \& H. M. Westerbeek. Sport as a vehicle for deploying corporate social responsibility, Journal of Corporate Citizenship, Vol. 25, 43-54, 2007.

[9] J. M. Gladden, D. F. Mahoney, \& A. Apostolopoulou. Toward a better understanding of college athletic donors: What are the primary motives? Sport Marketing Quarterly, Vol. 14, 18-30, 2005.

[10] J. Moon. Corporate social responsibility: A very short introduction. Oxford: Oxford University Press, 2014.

[11] A. Márquez \& C. J. Fombrun. Measuring Corporate Social Responsibility. Corporate Reputation Review, Vol. 7, No. 4, 304-308, 2005.

[12] P. Martínez, A. Pérez, \& I. Rodríguez del Bosque. Measuring corporate social responsibility in tourism: Development and validation of an efficient measurement scale in the hospitality industry. Journal of Travel \& Tourism Marketing, Vol. 30, No. 4, 365-385, 2013.

[13] T. J. Brown, \& P. A. Dacin. The company and the product: Corporate associations and consumer product responses. Journal of Marketing, Vol. 61, No. 1, 68-84, 1997.

[14] M. Walker, A. Kent, \& J. Vincent. Communicating socially responsible initiatives: An analysis of US professional teams. Sport Marketing Quarterly, Vol. 19, No. 4, 125-131, 2010.

[15] Y. J. Ko, Y. C. Rhee, Y. K. Kim, \& T. Kim. Perceived corporate social responsibility and donor behavior in college athletics: the mediating effects of trust and commitment. Sport Marketing Quarterly, Vol. 23, No. 2, 73-85, 2014.

[16] L. Marin, S. Ruiz, \& A. Rubio. The role of identity salience in the effects of corporate social responsibility on consumer behavior. Journal of Business Ethics, Vol., 84, No. 1, 65-78, 2009. 
[17] R. Levermore. Viewing CSR through sport from a critical perspective: Failing to address gross corporate misconduct? In J.L. Paramio-Salcines, K. Babiak \& G. Walters (Eds.), Routledge handbook of sport and corporate social responsibility, 52-61, London, England: Routledge, 2016.

[18] K. Babiak, R. Wolfe. Perspectives on social responsibility in sport. In J.L. Paramio-Salcines, K. Babiak, \& G. Walters (Eds.), Routledge handbook of sport and corporate social responsibility, 17-34, London, England: Routledge, 2016.

[19] Online Available: https://www.cnbc.com/2021/09/01/nfl-s ays-it-will-surpass-250-million-pledge-for-social-justice-w ork.html: J. Young, NFL says it will surpass \$250 million pledge for social justice work - now it wants new partnerships to address Black wealth gap, Online available from http://www.cnbc.com

[20] S. Trendafilova, K. Babiak, \& K. Heinze. Corporate social responsibility and environmental sustainability: Why professional sport is greening the playing field. Sport Management Review, Vol. 16, 298-313, 2013.

[21] S. Kim, Y. Kim, \& S. Lee. Motivation for giving to NCAA Division II Athletics. Sport Marketing Quarterly, Vol. 28, 77-90, 2019.

[22] K. A. Heard. The Impact of Preemption in the NFL Concussion Litigation. University of Miami Law Review, Vol. 68, 221-249, 2013.

[23] M. L. Wastyn. Why alumni don't give: A qualitative study of what motivates non-donors to higher education.
International Journal of Educational Advancement, Vol. 9 , No. 2, 96-108, 2009.

[24] F. K. Stage, H. C. Carter, \& A. Nora. Path analysis: An introduction and analysis of a decade of research. The Journal of Educational Research, Vol. 98, No. 1, 5-13, 2004.

[25] G. James, D. Witten, T. Hastie, \& R. Tibshirani. An introduction to statistical learning with application in R, Springer, New York, 2013.

[26] L. Hu \& P. M. Bentler. Cutoff criteria for fit indexes in covariance structure analysis: Conventional criteria versus new alternatives. Structural Equation Modeling, Vol. 6, No. $1,1-55,1999$

[27] B. M. Byrne. Structural Equation Modeling with AMOS: Basic Concepts, Applications, and Programming, Taylor \& Francis Group, New York, 2010.

[28] G. W. Cheung \& R. B. Rensvold. Evaluating goodness-of-fit indexes for testing measurement invariance. Structural Equation Modeling, Vol. 9, 233-255, 2002.

[29] M. Walker, A. Kent, \& J. Vincent. Communicating socially responsible initiatives: An analysis of US professional teams. Sport Marketing Quarterly, Vol. 19, No. 4, 125-131, 2010.

[30] M. Morsing \& M. Schultz. Corporate social responsibility communication: stakeholder information, response and involvement strategies. Business Ethics: A European Review, Vol. 15, No. 4, 323-338, 2006. 